CLINICAL STUDY

\title{
Lower insulin sensitivity differentiates hirsute from non-hirsute Sicilian women with polycystic ovary syndrome
}

\author{
Marco C Amato, Aldo Galluzzo, Simona Merlino, Antonina Mattina, Pierina Richiusa, Angela Criscimanna and \\ Carla Giordano \\ Endocrinology Section, Department of Experimental Oncology and Clinical Applications (DOSAC), Faculty of Medicine, Università degli Studi di Palermo, \\ Piazza Delle Cliniche 2, 90127, Palermo, Italy
}

(Correspondence should be addressed to C Giordano; Email: cgiordan@unipa.it)

\begin{abstract}
Objective: It is well known that hyperandrogenism and insulin-resistance with or without compensatory hyperinsulinism are closely associated, but the Rotterdam Consensus has concluded that principally obese women with polycystic ovary syndrome (PCOS) should be evaluated for the metabolic syndrome. Our aim was to study insulin sensitivity in PCOS women with hirsutism regardless of obesity.

Methods: Clinical characteristics, sex hormones and fasting- and after OGTT-glycemia and insulinemia, homeostatic model of insulin resistance (HOMA IR), and Matsuda index of insulin sensitivity were analyzed in 130 women with PCOS. Hirsutism has been evaluated through the Ferriman-Gallwey (FG) map scoring system.

Results: PCOS women with hirsutism (57.7\% of participants) showed significant higher values of total testosterone levels $(P=0.016)$, free testosterone $(P=0.027)$, DHEA sulfate $(P=0.017)$, and $\Delta$ 4androstenedione $(P=0.018)$. They had similar body mass index $(\mathrm{BMI})(P=0.073)$ and were significantly less insulin sensitive $(P=0.002)$ than those without hirsutism $(42.3 \%$ of participants $)$. In women with PCOS and hirsutism, there was a significant correlation between FG score and insulinsensitivity indexes (HOMA IR, $\rho=0.33, P=0.005$; Matsuda index, $\rho=-0.34, P=0.003$ ) but not with the androgen levels. Moreover, women with hirsutism showed a significantly greater insulin $(P=$ $0.019)$, C-peptide $(P=0.002)$, and glucose $(P=0.024)$ areas under the curve (auc2h).

Conclusions: Our study suggests that the increased responsiveness of the pilo-sebaceous unit to androgens seems to be influenced by insulin sensitivity and that insulin resistance should be assessed in all hirsute women with PCOS regardless of their BMI, as insulin resistance was found in hirsute women irrespective of whether they were overweight or obese.
\end{abstract}

European Journal of Endocrinology 155 859-865

\section{Introduction}

Polycystic ovary syndrome (PCOS) is the most common hormonal reproductive alteration in women of childbearing age, estimated in population-based studies with a prevalence of $5-10 \%(1-3)$. PCOS is characterized by hyperandrogenism, insulin resistance with or without compensatory hyperinsulinism (4), oligo-amenorrhea, hirsutism, acne, seborrhea, obesity, impaired glucose tolerance or type 2 diabetes, dyslipidemia, and infertility. The Rotterdam Consensus Conference (RCC) (5) proposed that the syndrome can be diagnosed after the exclusion of other medical conditions that cause irregular menstrual cycles and androgen excess (non-classical congenital adrenal hyperplasia, Cushing's syndrome, hyperprolactinemia, hypothyroidism, virilizing adrenal or ovarian neoplasm), and the determination that at least two of the following are present: oligoovulation or anovulation, elevated levels of circulating androgens and/or clinical hyperandrogenism, and polycystic ovaries as defined by ultrasonography. Furthermore, PCOS diagnosis requires the careful evaluation of associated metabolic disturbances, which may be responsible for several long-term complications, i.e. an increased risk of developing diabetes, dyslipidemia, cardiovascular disease, stroke, and endometrial carcinoma (6-9).

Considering the heterogeneity of PCOS, the Rotterdam Consensus has concluded that only obese women with PCOS should be screened for the metabolic syndrome. However, hyperinsulinemia and insulin resistance may play a major role in the development of most cases of PCOS, as hyperinsulinemia and insulin resistance precede hyperandrogenism $(10,11)$ and both lean and obese women with PCOS show insulin resistance, albeit with different severity $(12,13)$. Moreover, insulin-sensitizing agents, such as metformin or thiazolidinediones, slightly improve hyperandrogenic symptoms (14). Insulin acts synergistically with 
luteinizing hormone (LH) to enhance the androgen production of theca cells and inhibits hepatic synthesis of sex hormone binding globulin (SHBG), in turn increasing free bioavailable testosterone levels (15). In addition, specific biochemical defects allow the hyperandrogenism to become evident when insulin resistance occurs; a dysfunction in serine phosphorylation may be responsible for $\mathrm{P} 450 \mathrm{c} 17$ enhancement inducing the 17,20 lyase activity and subsequent androgen production. Likewise, increased serine phosphorylation of the insulin receptor impairs its tyrosine kinase activity and causes a reduction in insulin sensitivity (16). Our aim was to evaluate insulin sensitivity in PCOS women with or without hirsutism. The present study confirms the importance of evaluating insulin sensitivity together with biochemical hyperandrogenism mainly in PCOS women with hirsutism regardless of their body mass index (BMI).

\section{Materials and methods}

\section{Subjects}

The Institutional Review Board at the Faculty of Medicine of the University of Palermo approved the study. We retrospectively studied a group of 130 consecutive (2003-2005) women with PCOS in reproductive age (age range 16-42 years, mean age $=$ $24.56 \pm 5.2$ years), with mean BMI values of $30.13 \mathrm{Kg} / \mathrm{m}^{2}$ (s.D. $=6.96$; range $18-50$ ). All patients had been followed in our Outpatient Clinic. The diagnosis of PCOS was made on the basis of at least two of the following criteria, in agreement with the Rotterdam Consensus (5):

(i) clinically evident hyperandrogenism (hirsutism, evaluated with Ferriman-Gallwey (FG) score (17) and/or acne/seborrhea) and/or biochemical hyperandrogenism;

(ii) oligomenorrhea (irregular cycles > 34 days);

(iii) PCO (polycystic ovaries as defined by ultrasonography).

Amenorrhoic women (absence of vaginal bleeding $>6$ months) were excluded from the study because of their small number and various progesterone bleeding induction schemes, potentially interfering with hormonal pattern. Patients were asked about a family history of oligo-amenorrhea, hirsutism, and acne and for the modality of menarche. Weight, BMI, waist circumference and blood pressure were also evaluated. We also used the FG map scoring system, estimated from two observers, which has 11 domains depicting portions of the body. Hirsutism was defined as FG score $>8$ (17). Patients were tested for follicle-stimulating hormone (FSH), LH, 17- $\beta$ estradiol, 17-OH-progesterone, basal prolactin (PRL), total and free testosterone, DHEA sulfate (DHEAS), Androstenedione, total cholesterol, high density lipoprotein (HDL) cholesterol, low density lipoprotein (LDL) cholesterol, and triglycerides during the follicular phase (7th day). On the same day, we performed an oral glucose tolerance test (OGTT; 75 g glucose) and measured glycemia, insulinemia, C-peptide at 0, 30, 60, 90, and $120 \mathrm{~min}$. Progesterone levels were assessed again during the luteal phase (21st day). Biochemical hyperandrogenism was diagnosed when androgen levels were as follows: total testosterone $>2.08 \mathrm{nmol} / \mathrm{l}$, free testosterone $>6.94 \mathrm{pmol} / \mathrm{l}$, DHEAS $>11.69 \mu \mathrm{mol} / \mathrm{l}$, and androstenedione $>6.98 \mathrm{nmol} / \mathrm{l}$ (calculated on the basis of the 95th percentile upper limits of basal serum androgen normality in a control group of 30 healthy eumenorrhoic women without hirsutism and family history of PCOS).

Trans-vaginal ovary ultrasounds were performed on the 10th day from the beginning of the last period. Assessment of the pelvis was performed by transvaginal ultrasound using a $7.5 \mathrm{MHz}$ vaginal probe transducer (General Electric LOGIQ $400 \mathrm{MD}$ ). Both ovaries were measured in the sagittal, transverse, and coronal plane. Ovaries were classified as polycystic based on the presence of 12 or more follicles in each ovary measuring 2-8 $\mathrm{mm}$ in diameter, and/or increased ovarian volume (>10 ml) (5). The women treated with clomiphene citrate, oral contraceptives, anti-androgens, or drugs to control their appetite during the 6 months before the first visit were excluded from the study. Patients, who showed high PRL levels $(>25 \mu \mathrm{g} / \mathrm{l})$ on the 7 th day were screened on the following day for PRL pulse assay and excluded from the study if PRL was $>25 \mu \mathrm{g} / \mathrm{l}$ in at least two samples. We also excluded patients with 17-OH-Pg levels $>6.05 \mathrm{nmol} / \mathrm{l}$ who, after $250 \mu \mathrm{g}$ Synacthen, showed 17-OH-Pg $>30.26 \mathrm{nmol} / \mathrm{l}$ at $60 \mathrm{~min}$. Patients with DHEAS $>16.32 \mu \mathrm{mol} / \mathrm{l}$ were screened with a TC scan and excluded when adrenal hyperplasia or adenoma or virilizing androgen-secreting neoplasms were present. Cushing's syndrome was excluded when clinical and hormonal evaluation suggested its presence (phenotype, increased $24 \mathrm{~h}$ free urinary cortisol, high cortisol levels after $1 \mathrm{mg}$ of overnight dexamethasone). Clinical and biochemical euthyroidism had been previously assessed in all patients.

\section{Assays}

All hormones were measured in our laboratory using commercial kits. These included ELISA (DRG Diagnostics, DRG Instruments $\mathrm{GmbH}$, Germany) for $\mathrm{FSH}$ $(\mathrm{mUI} / \mathrm{ml}), \quad \mathrm{LH}(\mathrm{mUI} / \mathrm{ml}), \quad 17$ - $\beta$-estradiol $(\mathrm{pg} / \mathrm{ml})$, 17-OH-Pg (ng/ml), progesterone $(\mathrm{ng} / \mathrm{ml})$, PRL $(\mathrm{ng} / \mathrm{ml})$, total testosterone $(\mathrm{ng} / \mathrm{ml})$, free testosterone $(\mathrm{pg} / \mathrm{ml}$; the inter- and intra-run precision had a coefficient of variation $(\mathrm{CV})$ of 3.9 and $6.2 \%$ respectively; correlation with RIA and conventional equilibrium dialysis method was performed on 16 males and 19 females: coefficient of regression $r=0.97$; Pantec, Torino, Italy), androstenedione (ng/ml; Arnika, Milan, 
Italy), insulin (mUI/l; the intra- and interassay CVs were $\leq 4$ and $\leq 3.6 \%$ respectively) and $C$-peptide $(\mu \mathrm{U} / \mathrm{l})$; chemiluminescence assays were used for DHEAS $(\mu \mathrm{g} / \mathrm{dl})$. Blood glucose levels $(\mathrm{mg} / \mathrm{dl})$ were measured by the colorimetric method (Glucocard, Menarini Diagnostics, Italy). Total cholesterol, HDL, and triglycerides were measured in our central laboratory using standard assays. LDL cholesterol levels were calculated with Friedewald's formula. The conversion factors for the International System (SI) are: glucose (mg/dl vs mmol/l: 0.0555), insulin (mUI/l vs pmol/l: 6.0), total cholesterol (mg/dl vs mmol/l: 0.0258), total testosterone (ng/ml vs $\mathrm{nmol} / \mathrm{l}$ : 3.467), free testosterone $(\mathrm{pg} / \mathrm{ml}$ vs $\mathrm{pmol} / \mathrm{l}$ : 3.47), DHEAS ( $\mu \mathrm{g} / \mathrm{dl}$ vs $\mu \mathrm{mol} / \mathrm{l}: 0.0272)$, androstenedione (ng/ml vs nmol/l: 3.492), 17- $\beta$-estradiol $(\mathrm{pg} / \mathrm{ml}$ vs pmol/l: 3.671), 17-OH-Pg (ng/ml vs nmol/l: 3.026), progesterone $(\mathrm{ng} / \mathrm{ml}$ vs $\mathrm{nmol} / \mathrm{l}: 3.180)$, PRL $(\mathrm{ng} / \mathrm{ml}$ vs $\mu \mathrm{g} / \mathrm{l}: 1), \mathrm{FSH}$ (mUI/ml vs IU/l: 1 ), and $\mathrm{LH}(\mathrm{mUI} / \mathrm{ml}$ vs IU/l: 1).

Insulin sensitivity was estimated using basal insulin and glucose values to calculate homeostatic model of insulin resistance (HOMA IR) (18) (glycemia (mmol/l) $\times$ insulinemia $(\mu \mathrm{U} / \mathrm{ml}) / 22,5)$. The Matsuda index of insulin sensitivity (19) was calculated on the basis of glucose and insulin values during the OGTT (10 000/ glucose $(\mathrm{mg} / \mathrm{dl}) \times$ insulin $(\mu \mathrm{U} / \mathrm{ml}) \times$ glucose mean $\times$ insulin mean). These parameters are considered equivalent to the gold standard euglycemic hyperinsulinemic clamp (20). The area under the insulin and C-peptide curves during OGTT and area under the curve (AUC) glucose/AUC insulin ratio were also calculated.

\section{Statistical analysis}

We used the SPSS 11 software, Windows Edition (SPSS, Chicago, IL, USA), for all our statistical analysis. Continuous variables with normal distribution (age, BMI) were analyzed as mean values \pm s.D. and ranges; continuous variables without normal distribution were analyzed as median values and interquartile range. Rates and proportions were calculated for categorical data. As continuous variables were without normal distribution, we used non-parametric tests and differences were analyzed by Mann-Whitney U-test. Correlations among FG score, circulating androgens and insulin sensitivity indexes, in the subgroup of hirsute women, were determined by using the Spearman's test, the non-parametric equivalent for Pearson's test. $P<0.05$ was considered statistically significant. For categorical variables, differences were analyzed by means of the $\chi^{2}$-test and Fisher's exact test when appropriate.

\section{Results}

We studied a group of 130 women, aged from 16 to 42 years $(24.56 \pm 5.2$ s.D.), with a BMI value of
$30.13 \mathrm{Kg} / \mathrm{m}^{2} \pm 6.9$ s.D. Seventy-five women $(57.7 \%)$ were hirsute, 65 (50\%) had acne/seborrhea, 69 (53\%) had oligomenorrhea, $57(43.84 \%)$ had increased total testosterone, $80(61.53 \%)$ had increased free testosterone, 17 (13\%) had increased DHEAS, 80 (61.53\%) had increased $\Delta 4$-androstenedione, and 92 (70.76\%) had PCO. Patients were divided into two subgroups depending on the presence/absence of hirsutism (FG score $>8$; Tables 1 and 2) and their biochemical and clinical characteristics were analyzed. We found that women with hirsutism had BMI comparable to those without hirsutism $\left(31.19 \pm 7.36\right.$ vs $28.70 \pm 6.16 \mathrm{Kg} / \mathrm{m}^{2} ; P=$ 0.073; Table 1, Fig. 1). In addition, total and free testosterone, DHEAS, and $\Delta 4$-androstenedione levels were higher in hirsute women, but other sex hormones were comparable in the two groups (Table 1). Analyzing insulin sensitivity by HOMA IR and the Matsuda index, we found that patients without hirsutism had significantly higher insulin sensitivity than those with hirsutism (Table 2). Moreover, the insulin, C-peptide, and glycemic AUC2h during OGTT were notably higher in the hirsute women (Table 2). Finally, reduced HDL cholesterol (1.23 vs $1.72 \mathrm{mmol} / \mathrm{l}$, median values; $P<0.001)$ and increased triglycerides levels (0.91 vs $0.74 \mathrm{mmol} / \mathrm{l}$, median values; $P=0.022$ ) were observed in hirsute compared with non-hirsute women. No other statistical differences were observed for clinical and biochemical data. Moreover, there was a linear correlation among the different parameters in relation to the FG score in the subgroup with hirsutism (HOMA IR, Matsuda index, OGTT insulin AUC2h, and AUCglucose/AUCinsulin ratio; Table 3; Fig. 2). There was no correlation with androgen levels. Furthermore, a correlation between waist circumference and FG score was found in hirsute women $(\rho=0.283 ; P=0.018)$, differently from those without hirsutism $(\rho=-0.115$; $P=0.457)$.

Applying the current criteria for the diagnosis of the metabolic syndrome (21) in both groups of women affected by PCOS, we found that the metabolic syndrome was present in only $25.33 \%$ of hirsute women and in $14.54 \%$ of women without hirsutism $(P=$ NS, Table 4$)$. In addition, only $12 \%$ of PCOS women had fasting glucose $\geq 5.6 \mathrm{mmol} / \mathrm{l}$ or manifest type 2 diabetes, again with no different prevalence in the two groups. The group with hirsutism had lower HDL cholesterol levels than the non-hirsute one $(P<0.001$; Tables 2 and 4$)$. Triglycerides levels were significantly lower in women without hirsutism (Table 2), but when we classified women with $<1.7$ and $>1.7 \mathrm{mmol} / \mathrm{l}$ value $(21)$ no significant difference was detected (Table 4).

Dividing the whole cohort of patients into women with oligomenorrhea (69/130) and in women with regular menses (61/130), we found that oligomenorrhoic women had significantly lower progesterone levels during the luteal phase (21st day) (3.18 (1.59-8.90) $\mathrm{nmol} / \mathrm{l}$ vs $9.54(3.81-25.44) \mathrm{nmol} / \mathrm{l}$; median/interquartile range; $P<0.001)$. No other statistical 
Table 1 Clinical and hormonal parameters in women with and without hirsutism.

\begin{tabular}{|c|c|c|c|c|c|}
\hline & \multicolumn{2}{|c|}{ Women with hirsutism $(n=75)$} & \multicolumn{2}{|c|}{ Women without hirsutism $(n=55)$} & \multirow[b]{2}{*}{$P$ value } \\
\hline & Mean \pm S.D. & Range & Mean \pm s.D. & Range & \\
\hline \multicolumn{6}{|c|}{ Clinical characteristics } \\
\hline $\begin{array}{l}\text { Age } \\
\text { BMI }\end{array}$ & $\begin{array}{l}24.72 \pm 5.83 \\
31.19 \pm 7.36\end{array}$ & $\begin{array}{l}16-42 \\
18-50\end{array}$ & $\begin{array}{l}24.35 \pm 4.28 \\
28.70 \pm 6.16\end{array}$ & $\begin{array}{l}18-32 \\
18-42\end{array}$ & $\begin{array}{l}0.975 \\
0.073\end{array}$ \\
\hline & Median & Interquartile range & Median & Interquartile range & \\
\hline Menarche age & 12 & $11-13$ & $11.84 \pm 1.53$ & & 0.616 \\
\hline $\begin{array}{l}\text { Systolic blood } \\
\text { pressure }\end{array}$ & 110 & $110-120$ & 115 & $110-120$ & 0.571 \\
\hline $\begin{array}{l}\text { Diastolic blood } \\
\text { pressure }\end{array}$ & 70 & $70-80$ & 70 & $70-80$ & 0.481 \\
\hline Waist $(\mathrm{cm})$ & 88 & $78-100$ & 88 & $80-100$ & 0.868 \\
\hline FG score & 18.5 & $12.75-22$ & 7 & $5-7$ & $0.000^{*}$ \\
\hline Family history & \multicolumn{2}{|c|}{ Subjects (\%) } & \multicolumn{2}{|c|}{ Subjects (\%) } & 0.927 \\
\hline Diagnostic criteria acc & ccording to Ro & Consensus & & & \\
\hline & & $(\%)$ & & ts $(\%)$ & \\
\hline Acne/seborrhea & & & & .09) & 0.859 \\
\hline Oligomenorrhea & & & & $.54)$ & 0.611 \\
\hline PCO & & & & $.54)$ & 0.418 \\
\hline Biochemical hyperanc & adrogenism & & & & \\
\hline Increased total test & tosterone & & & & 0.449 \\
\hline Increased free test & tosterone & & & (90) & $0.033^{*}$ \\
\hline Increased DHEAS & & & & 72) & 0.919 \\
\hline Increased $\Delta 4$ andro & ostenedione & & & 18) & 0.501 \\
\hline Hormonal pattern & & & & & \\
\hline & Median & Interquartile range & Median & Interquartile range & \\
\hline $\mathrm{FSH}(\mathrm{IU} / \mathrm{l})$ & 6.72 & $5.09-9$ & 7.10 & $6.4-7.9$ & 0.677 \\
\hline $\mathrm{LH}(\mathrm{IU} / \mathrm{I})$ & 7.9 & $4.05-13$ & 8.2 & $5.7-11$ & 0.836 \\
\hline $\mathrm{LH} / \mathrm{FSH}$ & 1.18 & $0.64-1.6$ & 1.07 & $0.82-1.5$ & 0.849 \\
\hline $\begin{array}{l}17-\beta \text {-estradiol } \\
(\mathrm{pmol} / \mathrm{l})\end{array}$ & 135.82 & $99.11-187.03$ & 144.63 & 102.78-201.90 & 0.179 \\
\hline $\begin{array}{c}17-\mathrm{OH}-\mathrm{Pg} \\
(\mathrm{nmol} / \mathrm{l})\end{array}$ & 4.23 & $2.54-6.35$ & 3.63 & $2.57-6.65$ & 0.653 \\
\hline $\begin{array}{l}\text { Progesterone } \\
\text { (nmol/l) }\end{array}$ & 4.45 & $2.48-19.84$ & 4.45 & $1.84-13.67$ & 0.451 \\
\hline Basal PRL $(\mu \mathrm{g} / \mathrm{l})$ & 9.5 & $6.96-15.6$ & 11.4 & $7.5-13.9$ & 0.382 \\
\hline $\begin{array}{l}\text { Total testosterone } \\
(\mathrm{nmol} / \mathrm{l})\end{array}$ & 1.97 & $1.45-2.77$ & 1.45 & $0.55-2.60$ & $0.016^{*}$ \\
\hline $\begin{array}{l}\text { Free testosterone } \\
\quad(\mathrm{pmol} / \mathrm{l})\end{array}$ & 9.23 & $5.72-13.35$ & 6.94 & $3.81-9.02$ & $0.027^{*}$ \\
\hline DHEAS $(\mu \mathrm{mol} / \mathrm{l})$ & 7.43 & $5.29-9.94$ & 5.64 & $3.91-8.01$ & $0.017^{*}$ \\
\hline $\begin{array}{l}\Delta \text { 4androstene- } \\
\text { dione }(\mathrm{nmol} / \mathrm{l})\end{array}$ & 8.03 & $5.93-10.47$ & 6.98 & $5.93-8.38$ & $0.018^{*}$ \\
\hline
\end{tabular}

BMI, body mass index; FG, Ferrimen-Gallwey; PCO, polycystic ovaries; FSH, follicle-stimulating hormone; $\mathrm{LH}$, luteinizing hormone; 17-OH-Pg, 17-OHprogesterone; PRL, prolactin. *Significant values when $P<0.05$.

differences were observed for clinical, hormonal, and metabolic variables (data not shown).

\section{Discussion}

The presence of insulin resistance and compensatory hyperinsulinemia in mainly obese women with PCOS is considered a key factor in the development of hyperandrogenism (22). Nevertheless, the diagnosis of PCOS is still difficult, especially considering the heterogeneity of clinical phenotypes and laboratory findings. It would be helpful to develop improved diagnostic criteria based on a particular clinical phenotype, i.e. hirsutism, oligomenorrhea or obesity. In our study, we confirm the complexity of this syndrome by studying a sample of affected women from Sicily, in whom we evaluated different biochemical and metabolic patterns in relation to the presence or absence of hirsutism. Acne/ seborrhea, menstrual cycle, and PCO did not differ in PCOS women with or without hirsutism. The reduced insulin sensitivity in hirsute women per se suggests that, in these women, decreased insulin sensitivity plays a significant role, as also indicated by our analysis: we found a high correlation between FG score and all the insulin sensitivity indexes in hirsute women, while this 
Table 2 Metabolic parameters in women with and without hirsutism.

\begin{tabular}{|c|c|c|c|c|c|}
\hline & \multicolumn{2}{|c|}{ Women with hirsutism $(n=75)$} & \multicolumn{2}{|c|}{ Women without hirsutism $(n=55)$} & \\
\hline & Median & Interquartile range & Median & Interquartile range & \\
\hline Total Cholesterol (mmol/l) & 4.66 & $4.04-5.41$ & 4.97 & $4.02-5.76$ & 0.703 \\
\hline HDL Cholesterol ( $\mathrm{mmol} / \mathrm{l})$ & 1.23 & $1.08-1.36$ & 1.72 & $1.23-2.08$ & $<0.001^{*}$ \\
\hline LDL Cholesterol $(\mathrm{mmol} / \mathrm{l})$ & 2.83 & $2.36-3.84$ & 2.96 & $1.87-3.60$ & 0.262 \\
\hline Triglycerides $(\mathrm{mmol} / \mathrm{l})$ & 0.91 & $0.73-1.26$ & 0.74 & $0.47-1.19$ & $0.022^{*}$ \\
\hline Fasting glucose (mmol/l) & 4.66 & $4.32-5.32$ & 4.82 & $4.49-5.14$ & 0.356 \\
\hline Fasting insulin $(\mathrm{pmol} / \mathrm{l})$ & 108.6 & $67.2-169.8$ & 72.3 & $46.62-105.6$ & $0.002^{*}$ \\
\hline Fasting C-peptide $(\mu \mathrm{U} / \mathrm{l})$ & 2.1 & $0.8-4.27$ & 1.2 & $0.9-3.6$ & 0.568 \\
\hline Glucose $120 \mathrm{~min}(\mathrm{mmol} / \mathrm{l})$ & 5.88 & $4.77-6.93$ & 4.82 & $4.03-5.99$ & $0.007^{*}$ \\
\hline Insulin $120 \mathrm{~min}(\mathrm{pmol} / \mathrm{l})$ & 454.8 & $254.7-930.42$ & 450.6 & $156-666$ & 0.109 \\
\hline C-peptide $120 \mathrm{~min}(\mu \mathrm{U} / \mathrm{l})$ & 8.9 & $6.6-11.6$ & 7.5 & $4.8-9.4$ & $0.005^{*}$ \\
\hline HOMA IR & 4.08 & $2.30-6.51$ & 2.49 & $1.56-3.77$ & $0.002^{*}$ \\
\hline Matsuda index & 2.6 & $1.82-4.8$ & 3.68 & $2.51-6.03$ & $0.002^{*}$ \\
\hline AUC2h glycemia & 768.39 & $644.74-863.30$ & 687.64 & $593.57-780.05$ & $0.024^{*}$ \\
\hline AUC2h IRI & 61242 & $39402-112680$ & 48960 & $29430-68778$ & $0.019^{*}$ \\
\hline AUC2h plasmatic C-peptide & 984 & $732-1442$ & 785 & $637-1016$ & $0.002^{*}$ \\
\hline AUC2hgl/AUC2hIRI ratio & 0.012 & $0.0075-0.017$ & 0.014 & $0.0095-0.024$ & 0.057 \\
\hline
\end{tabular}

HDL, high density lipoprotein; LDL, low density lipoprotein; HOMA IR, homeostatic model assessment of insulin resistance; AUC, area under curve; IRI, insulin resistance index. *Significant values when $P<0.05$.

relation was not observed between FG and circulating androgens. In our study, a higher FG score is associated with decreased insulin sensitivity. With regards to BMI, it is noteworthy that in our cohort we also found hirsute women with insulin resistance and normal weight. This suggests that the responsiveness of the pilo-sebaceous unit to androgen levels could be affected by decreased insulin sensitivity. In addition, the effect of insulin and the insulin-like growth factor (IGF) system has been accurately investigated in vitro (23), and some authors (24) have shown that insulin/IGF plays a role in stimulating hair follicle growth acting together with androgens. Other authors suggest that also idiopathic hirsutism is associated with insulin resistance and an increased prevalence of impaired glucose tolerance (25). However, it still remains unclear if the correlation we found between insulin sensitivity and FG score is due to insulin resistance or compensatory hyperinsulinism (26). In fact, it is extremely difficult to evaluate the effect of insulin resistance/hyperinsulinism on the response to androgens of the pilo-sebaceous unit by the measure of the activity of 5 - $\alpha$-reductase. Circulating dihydroxytestosterone is not related to intracellular hormone levels, and its evaluation through the metabolite 3- $\alpha$-androstenedione glucuronide is strongly influenced by the liver component, which is higher than the cutaneous one. In addition, it still remains to be established whether our Sicilian PCOS women are more susceptible to develop the metabolic syndrome for their genetic predisposition or environmental factors and this may influence their hirsutism prevalence. In this light, it is to be noted that our cohort of patients is constituted by women in reproductive age and possibly they will develop metabolic syndrome after menopause.

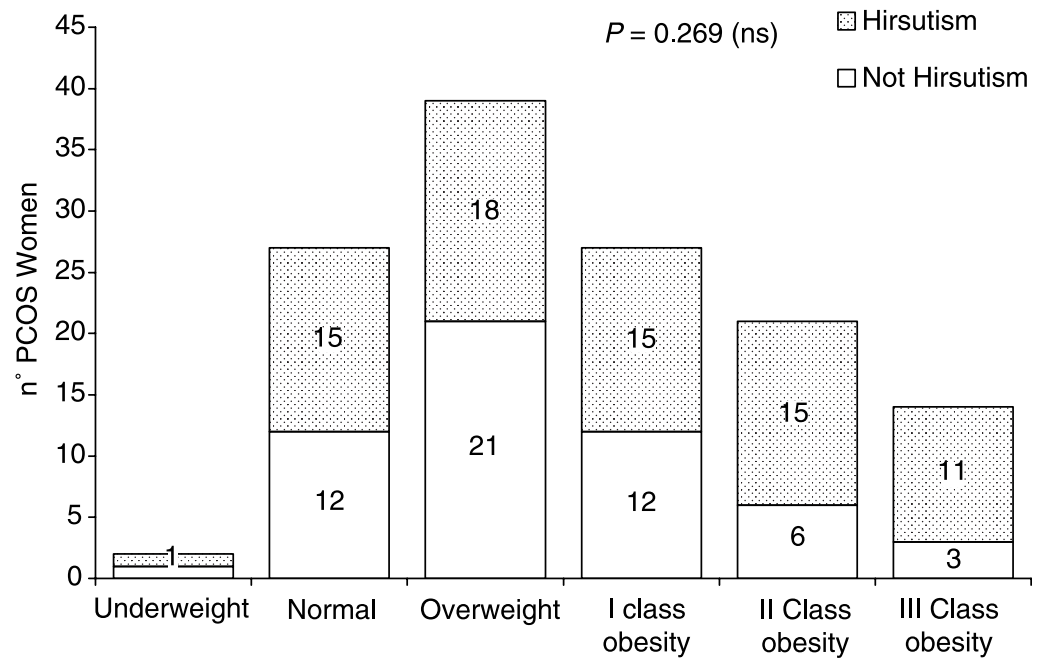

Figure 1 Class of obesity in polycystic ovary syndrome (PCOS) women with or without hirsutism. Patients with PCOS divided on the basis of body mass index are equally distributed in relation to presence or absence of hirsutism. 
Table 3 Correlation between insulin sensitivity indexes, androgen levels, and Ferriman-Gallwey (FG) score in the subgroup of hirsute women.

\begin{tabular}{lcc}
\hline & Sperman $\boldsymbol{\rho}$ coefficient & $\boldsymbol{P}$ value \\
\hline HOMA IR & 0.330 & $0.005^{\star}$ \\
Matsuda index & -0.344 & $0.003^{*}$ \\
AUCglyc/AUCins & -0.235 & $0.047^{*}$ \\
AUC glycemia & -0.002 & 0.984 \\
AUC insulinemia & 0.249 & $0.034^{*}$ \\
AUC c-peptide & 0.108 & 0.366 \\
Testosterone & -0.281 & 0.053 \\
Free testosterone & 0.158 & 0.183 \\
DHEAS & -0.033 & 0.782 \\
$\Delta 4$ Androstenedione & 0.079 & 0.506 \\
\hline
\end{tabular}

AUC, area under curve. * Significant values when $P<0.05$.

Our findings lead us to hypothesize that the metabolic abnormalities could have an impact after the menopause in PCOS women (27). Diabetes mellitus, hyperlipidemia, and hyperinsulinemia could potentially affect health in this era of life in the hirsute PCOS women. In our study, the prevalence of fasting glycemia $\geq 5.6 \mathrm{mmol} / \mathrm{l}$ or manifest type 2 diabetes (21) was around $15 \%$, not different with respect to other PCOS women cohorts.

In conclusion, the evaluation of insulin sensitivity by fasting/after OGTT insulinemia is as useful as the screening for circulating androgens in PCOS women
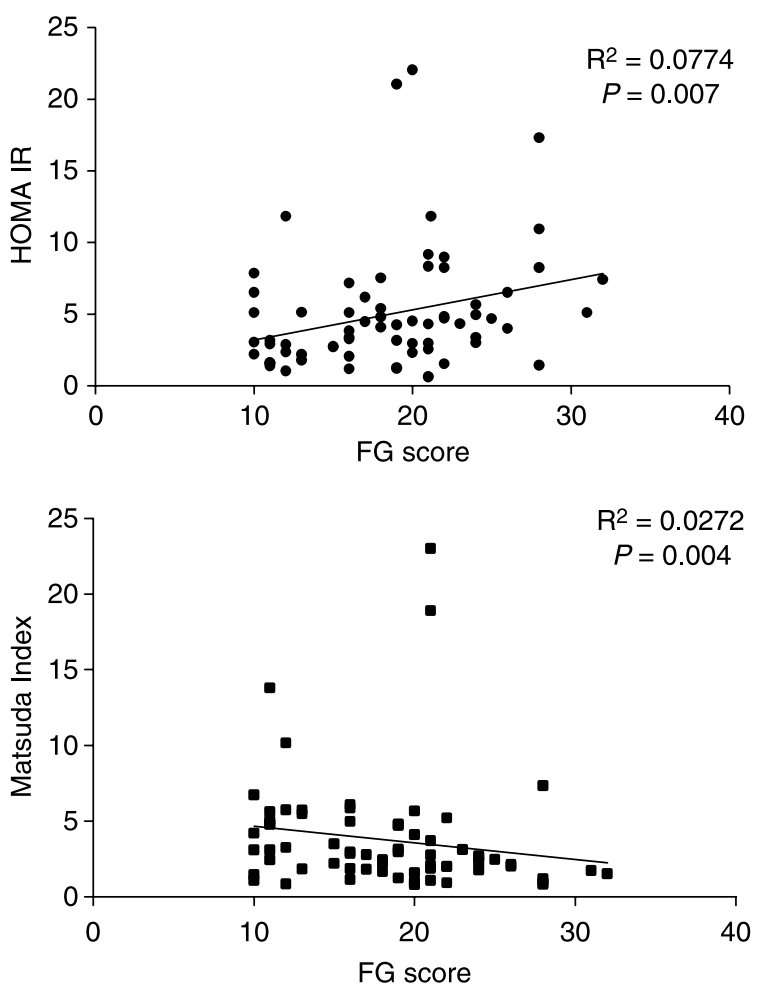

Figure 2 Correlation between Ferriman-Gallwey (FG) score and insulin sensitivity indexes (HOMA IR, Matsuda) in the subgroup of hirsute women.
Table 4 Metabolic syndrome according to the new International Diabetes Federation (IDF) definition in women with and without hirsutism.

\begin{tabular}{|c|c|c|c|}
\hline & \multicolumn{2}{|c|}{ Subjects (\%) } & \multirow[b]{2}{*}{$P$ value } \\
\hline & $\begin{array}{l}\text { Women } \\
\text { with hir- } \\
\text { sutism } \\
(n=75)\end{array}$ & $\begin{array}{l}\text { Women } \\
\text { without } \\
\text { hirsutism } \\
(n=55)\end{array}$ & \\
\hline Metabolic syndrome & $19(25.33)$ & $8(14.54)$ & 0.134 \\
\hline $\begin{array}{l}\text { Waist circumference } \\
\geq 80 \mathrm{~cm}\end{array}$ & $51(68)$ & 37 (67.27) & 0.119 \\
\hline $\begin{array}{l}T_{\mathrm{g}} \geq 1.7 \mathrm{mmol} / \mathrm{l} \text { or specific } \\
\text { treatment }\end{array}$ & $7(9.33)$ & $6(10.9)$ & 0.767 \\
\hline $\begin{array}{l}\text { HDL cholesterol } \\
\leq 1.29 \mathrm{mmol} / \mathrm{l} \text { or specific } \\
\text { treatment }\end{array}$ & $47(62.66)$ & $15(27.27)$ & $<0.001^{\star}$ \\
\hline $\begin{array}{l}\text { Systolic BP } \geq 130 \mathrm{mmHg} \\
\text { or diastolic BP } \\
\geq 85 \mathrm{mmHg} \text { or specific } \\
\text { treatment }\end{array}$ & $6(8)$ & $9(16.36)$ & 0.140 \\
\hline $\begin{array}{l}\text { Fasting glucose } \\
\geq 5.6 \mathrm{mmol} / \mathrm{l} \text { or } \\
\text { previously diagnosed } \\
\text { type } 2 \text { diabetes }\end{array}$ & $12(16)$ & $8(14.54)$ & 0.820 \\
\hline
\end{tabular}

$\mathrm{T}_{\mathrm{g}}$, triglycerides; HDL, high density lipoprotein; $\mathrm{BP}$, blood pressure. *Significant values when $P<0.05$.

with hirsutism. In this light, it is noteworthy that recent work suggested that more practical fasting measures of insulin sensitivity by the HOMA model equate well with measures requiring a $2 \mathrm{~h}$ glucose tolerance test $(28)$ and that fasting blood tests for glucose and insulin may be sufficient to determine insulin sensitivity in the clinic context. It is to be noted that a certain controversy still persists regarding the application of mathematical indices in different insulin-resistant populations as they cannot be considered a priori equivalent to the euglycemic clamp technique (29). In addition, our findings seem to confirm that evaluation of the hypothalamic-pituitary-ovary axis should be performed in PCOS women with oligomenorrhea, with special attention to progesterone levels in the luteal phase.

Our data suggest that in the Sicilian population the evaluation of insulin sensitivity indexes in hirsute women with normal levels of circulating androgens could help to diagnose PCOS, which is important given the high prevalence of metabolic syndrome in women with this condition.

\section{References}

1 Knochenhauer ES, Key TJ, Kahsar-Miller M, Waggoner W, Boots LR \& Azziz R. Prevalence of the polycystic ovary syndrome in unselected black and white women of the southeastern United States: a prospective study. Journal of Clinical Endocrinology and Metabolism 199883 3078-3082.

2 Diamanti-Kandarakis E, Kouli CR, Bergiele AT, Filandra FA, Tsianateli TC, Spina GG, Zapanti ED \& Bartzis MI. A survey of 
the polycystic ovary syndrome in the Greek island of Lesbos: hormonal and metabolic profile. Journal of Clinical Endocrinology and Metabolism $1999 \mathbf{8 4}$ 4006-4011.

3 Azziz R, Woods KS, Reyna R, Key TJ, Knochenhauer ES \& Yildiz BO. The prevalence and features of polycystic ovary syndrome in an unselected population. Journal of Clinical Endocrinology and Metabolism 200489 2745-2749.

4 Livingstone C \& Collison M. Sex steroids and insulin resistance. Clinical Science 2002102 151-166.

5 The Rotterdam ESHRE/ASRM-sponsored PCOS consensus workshop group. Revised 2003 consensus on diagnostic criteria and long-term health risks related to polycystic ovary syndrome (PCOS). Human Reproduction 20041 41-47.

6 Taylor AE. Polycystic ovary syndrome. Endocrinology and Metabolism Clinics of North America 19984 877-902.

7 Poretsky L, Cataldo NA, Rosenwaks Z \& Giudice LC. The insulinrelated ovarian regulatory system in health and disease. Endocrinology Review 199920 535-582.

8 Sukalich S \& Guzick D. Cardiovascular health in women with polycystic ovary syndrome. Seminars in Reproductive Medicine 2003 21 309-315.

9 Hardiman P, Pillay OC \& Atiomo W. Polycystic ovary syndrome and endometrial carcinoma. Lancet $2003 \mathbf{3 6 1} 1810-1812$.

10 Poretsky L. On the paradox of insulin-induced hyperandrogenism in insulin resistant states. Endocrinology Review 199112 3-13.

11 Cenk Sayin N, Gucer F, Balkanli-Kaplan P, Ali Yuce M \& Yardim T. Insulin resistance and lipid profile in women with polycystic appearing ovaries: implications with regard to polycystic ovary syndrome. Gynecological Endocrinology 200317 387-396.

12 Dunaif A, Segal KR, Futterweit W \& Dobrjansky A. Profound peripheral insulin resistance, indipendent of obesity, in polycystic ovary syndrome. Diabetes 198938 1165-1174.

13 Van Dam EW, Roelfsema F, Veldhuis JD, Hogendoorn S, Westenberg J, Helmerhorst FM, Frolich M, Krans HM, Meinders AE \& Pijl H. Retention of estradiol negative feedback relationship to $\mathrm{LH}$ predicts ovulation in response to caloric restriction and weight loss in obese patients with polycystic ovary syndrome. American Journal of Physiology-Endocrinology and Metabolism 2004286 615-620.

14 Pasquali Rand Gambineri A. Insulin-sensitizing agents in polycystic ovary sindrome. European Journal of Endocrinology $2006154763-775$.

15 Ehrmann DA. Polycistic ovary syndrome. New England Journal of Medicine $20053521223-1236$.

16 Zhang LH, Rodriguez H, Ohno S \& Miller WL. Serine phosphorylation of human P450c17 increases 17,20 lyase activity: implications for adrenarche and the polycystic ovary syndrome. PNAS 199592 10619-10623.
17 Ferriman D \& Gallwey JD. Clinical assessment of body hair growth in women. Journal of Clinical Endocrinology and Metabolism 1961 21 1440-1447.

18 Matthews DR, Hosker JP, Rudenski AS, Naylor BA, Treacher DF \& Turner RC. Homeostasis model assessment: insulin resistance and $\beta$ cell function from fasting plasma glucose and insulin in man. Diabetologia 198528 412-419.

19 Matsuda M \& De Fronzo RA. Insulin sensitivity indices obtained from oral glucose tolerance testing: comparison with the euglycemic insulin clamp. Diabetes Care 200124 460-464.

20 Radikova Z. Assessment of insulin sensitivity/resistance in epidemiological studies. Endocrine Regulation 200337 189-194.

21 The IDFconsensus worldwide definition of the metabolic syndrome [article on line]. Available from http://www.idf.org, 2005.

22 Sozen I \& Arici A. Hyperinsulinism and its interaction with hyperandrogenism in polycystic ovary syndrome. Obstetrical and Gynecological Survey $2000 \mathbf{5 5} 321-328$.

23 Philpott MP, Sanders DA \& Kealey T. Effects of insulin and insulinlike growth factors on cultured human hair follicles: IGF-I at physiologic concentrations is an important regulator of hair follicle growth in vitro. Journal of Investigative Dermatology 1994 102 857-861.

24 Itami S, Kurata S \& Takayasu S. Androgen induction of follicular epithelial cell growth is mediated via insulin-like growth factor-I from dermal papilla cells. Biochemical and Biophysical Research Communications $1995212988-994$.

25 Ünlühizarci K, Karababa Y, Bayram F \& Kelestimur F. The investigation of insulin resistance in patients with Idiopathic Hirsutism. Journal of Clinical Endocrinology and Metabolism 2004 89 2741-2744.

26 Falsetti L, Gambera A, Andrico S \& Sartori E. Acne and hirsutism in polycystic ovary syndrome: clinical, endocrine-metabolic and ultrasonographic differences. Gynecological Endocrinology 200216 275-284.

27 Norman RJ \& McVeigh E. Polycystic ovary syndrome and implications for the menopause. Climacteric $19992141-143$.

28 Heald A, Whitehead S, Anderson S, Cruickshank K, Riste L, Laing I, Rudenski A \& Buckler H. Screening for insulin resistance in women with polycystic ovarian syndrome. Gynecological Endocrinology $2005 \mathbf{2 0} 84-91$.

29 Diamanti-Kandarakis E, Kouli C, Alexandraki K \& Spina G. Failure of mathematical indices to accurately assess insulin resistance in lean, overweight, or obese Women with Polycystic Ovary Syndrome. Journal of Clinical Endocrinology and Metabolism 2004 89 1273-1276.

Received 27 February 2006

Accepted 12 September 2006 